\title{
Solitary Plasmocytoma of the Vault
}

\section{Baallal $\mathrm{H}^{*}$, Gazzaz M, Akhaddar A and El mostarchid B}

Department of Neurosurgery, Mohammed V Military Teaching Hospital, University of King Mohammed V Souissi, Rabat, Morocco

\begin{abstract}
Solitary plasmocytoma is rarely located in the cranial vault. We report a case of a 46-year-old Moroccan man who consulted for a medial and paramedian frontal swelling. Clinical examination revealed a large soft mass in the region frontal. Computed tomography and magnetic resonance imaging revealed an extra-axial mass. The lesion was totally excised despite the bleeding tendency. Histology disclosed the presence of a plasmacytoma. On follow up examination 3 years later no tumor recurrence or multiple myeloma was detected.
\end{abstract}

Keywords: Solitary plasmocytoma; Cranial vault; Multiple myeloma

\section{Introduction}

The solitary plasmacytoma is a rare malignant tumor, represented by a single plasma cell proliferation derived from a single clone of $\mathrm{B}$ cells more or less differentiated. It is close to multiple myeloma but distinguished by its isolated nature and often slow evolution. Craniocerebral localization is rare and constitutes only 0.7 per 100 of all solitary plasmacytomas. They fall into two groups [1]. Those arising from the cranial bones (plasmacytoma of the skull, osseous form) and those arising from the dura mater (dural plasmacytoma, non-osseous form).

We report one case of solitary plasmacytoma of the skull and discuss the clinical features and treatment of this uncommon tumor in the light of the published cases.

\section{Case Report}

A 46-year-old Moroccan man, without any medical history consulted for a medial and paramedian frontal swelling and painless that appeared 6 months ago and had gradually enlarged. The patient suffered from headache during last months without alterations in mental status.

The clinical examination revealed a right ipsilateral Babinski and a large soft mass in the frontal region.

The skull radiograph showed an ill-defined gap of the frontal bone. Computed tomography showed a frontal osseous lesion with an electron density slightly greater than the brain and contrast enhancement (Figure 1).

Magnetic resonance imaging (MRI) showed an extra-axial process centered on the frontal bone, isointense in $\mathrm{T} 1$ weighted images relative to brain parenchyma (Figure 1) and heterogeneous in T2 weighted images. Injection of gadolinium revealed an important enhancement (Figure 1).

The process presented an endocranial extension with mass effect on the cerebral convolutions and an extracranial extension distorting the skin contours. Immunoelectrophoresis of proteins, proteinuria (24 hours) and the myelogram in search of multiple myeloma were without abnormalities.

Treatment consisted of surgical resection by bifrontal craniotomy followed by macroscopically total removal of a nodular tumor that was adherent but not infiltrating the dura. The histological diagnosis matched with a plasmacytoma.

After 3 years of follow up, no tumor recurrence or evidence of multiple myeloma was detected.

\section{Discussion}

Plasmacytomas are clonal proliferations of plasma cells that are cytologically and immunophenotypically identical to plasma cell myeloma but manifest a localized osseous or extraosseous growth pattern. Extramedullary plasmacytoma is rare and occur only in $2 \%$ to $10 \%$ of newly diagnosed patients with multiple myeloma. Primary extramedullary plasmacytomas are uncommon, accounting for $4 \%$ of all plasma cell tumors, mainly arising in the head and neck, particularly the upper aerodigestive tract. Cranial and intracranial plasmacytomas may involve cranial vault and/or the skull base [2-8].

The incidence of solitary plasmacytoma has been reported to be approximately $3 / 100,000$ annually, increasing with the age of the patient, with a median presentation of 60 years of age.' Most patients are males, with reported male:female ratio as high as $4 / 1$.

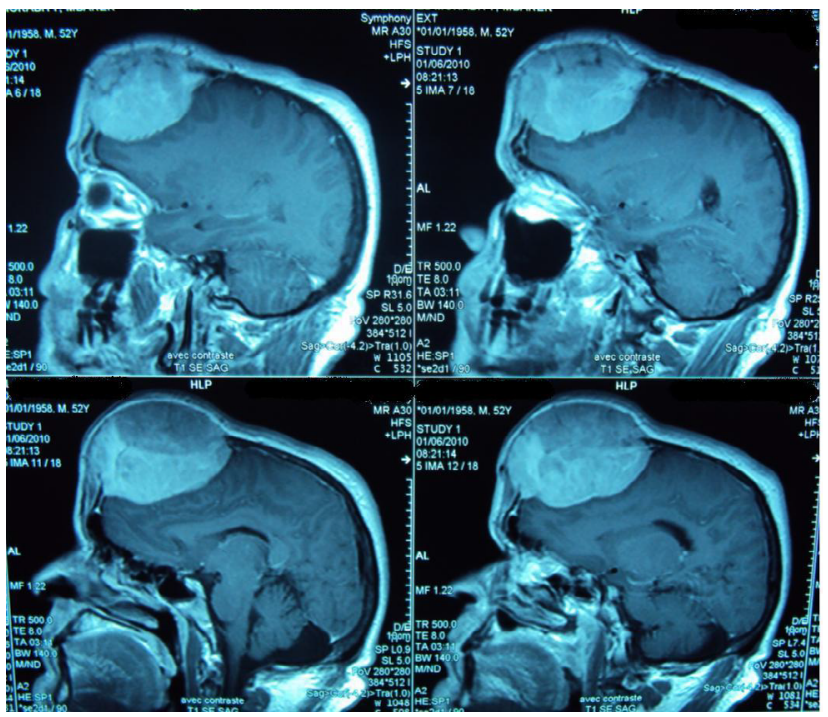

Figure 1: Sagittal T1 MRI post gadolinium showing a frontal extra axia lesionwith important enhancement of the lesion.

*Corresponding author: Hassan Baallal, Department of Neurosurgery, Mohammed V Military Teaching Hospital, University of King Mohammed V Souissi, Rabat, Morocco, Tel: 212652304617; E-mail: baallalnch@gmail.com

Received April 15, 2014; Accepted May 26, 2014; Published May 28, 2014

Citation: Baallal H, Gazzaz M, Akhaddar A, El mostarchid B (2014) Solitary Plasmocytoma of the Vault. Med chem 4: 449-450. doi:10.4172/2161-0444.1000178

Copyright: @ 2014 Baallal $\mathrm{H}$, et al. This is an open-access article distributed under the terms of the Creative Commons Attribution License, which permits unrestricted use, distribution, and reproduction in any medium, provided the original author and source are credited. 
Citation: Baallal H, Gazzaz M, Akhaddar A, El mostarchid B (2014) Solitary Plasmocytoma of the Vault. Med chem 4: 449-450. doi:10.4172/21610444.1000178

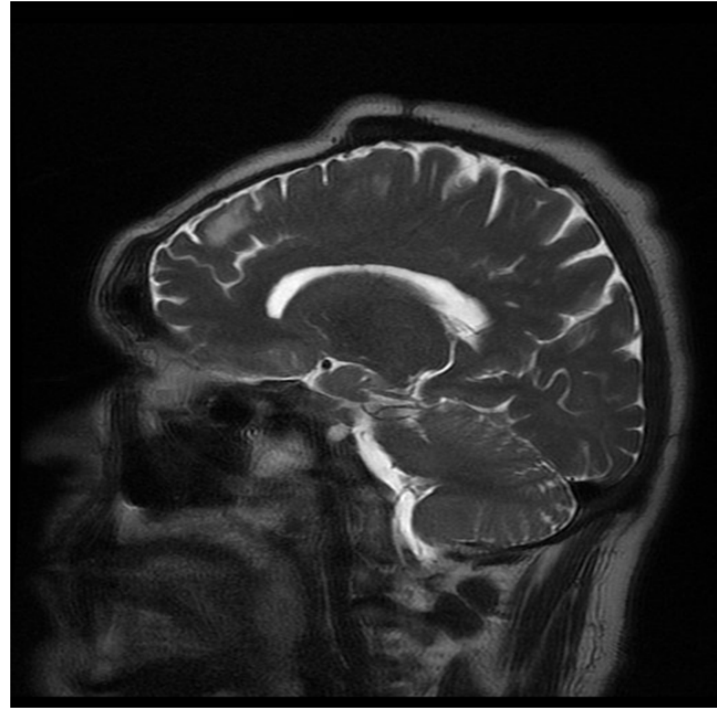

Figure 2: Sagittal T2 MRI showing complete resection of tumor.

Approximately half of patients have a monoclonal gammopathy detectable on serum or urine electrophoresis [3]. The incidence rate of solitary plasmocytoma in black race is approximately $30 \%$ higher than the white race [9].

The craniocerebral plasmacytoma arises in dura, skull bones or more rarely in brain [10]. Tumors of the skull are dominated by frequency secondary location. Primitive cranial tumors represent less than 2 per 100 of all primary bone tumors.

The location at the vault plasmacytoma is extremely rare [11].

Symptoms and signs are not specific with any neurological symptoms except of intraparenchymal extension or compression of brain and cranial nerves [4]. In this case, symptomatology depends on the lesion's location [12]. Cosmetic skull deformities have been reported to be a usual cause for referring to a specialist [13]. Except from the severe clinical deterioration, a problem of cosmetic appearance was also evident in our patient.

Total surgical resection followed by adjunctive radiationtherapy has been advocated as an effective treatment in the majority of skull plasmacytomas [11]. Our patient underwent surgery with complete resection of tumor (Figure 2).

Nevertheless, Arienta et al. reported that if total resection has been achieved then radiotherapy should be reserved for case of tumor recurrence [1]. Furthermore, there are reports of complete cure after radiotherapy, because plasma cell neoplasms are exquisitely radiosensitive [14]. In our case because of the complete tumoral excision, regular follow-up was preferred reserving radiotherapy for the future. The magnetic resonance imaging control was satisfactory.

Intraoperative, plasmacytoma may be a highly vascular tumor, therefore the neurosurgeon should be careful to perform a thorough hemostasis. A case of cardiac arrest from excessive blood loss has been reported [11].

Although the prognosis of a plasmocytoma is relatively good [15]. Clinicians should therefore be careful in the follow-up period because there is always a risk of recurrence.

\section{Conclusion}

The solitary plasmacytoma, although rare, should be among the diagnostics to discuss in the case of a lytic lesion of the cranial vault. However, skeletal radiographs and a bone marrow biopsy is needed to confirm the diagnosis of solitary plasmacytoma and to eliminate systemic multiple myeloma. Surgery with radiotherapy is the most effective therapeutic modality of bone plasmocytoma solitary allowing local control over $95 \%$ of cases.

\section{References}

1. Arienta C, Caroli M, Ceretti L, Villani R (1987) Solitary plasmacytoma of the calvarium: two cases treated by operation alone. Neurosurgery 21: 560-563.

2. Kotner LM, Wang CC (1972) Plasmacytoma of the upper air and food passages Cancer 30: 414-418.

3. Alexanian R (1978) Plasma cell neoplasms. Cur Prob Cancer 3: I-60.

4. Mancardi GL, Mandybur TI (1983) Solitary intracranial plasmacytoma. Cancer 51: 2226-2233.

5. CLARKE E (1954) Cranial and intracranial myelomas. Brain 77: 61-81.

6. Schwartz TH, Rhiew R, Isaacson SR, Orazi A, Bruce JN (2001) Association between intracranial plasmacytoma and multiple myeloma: clinicopathological outcome study. Neurosurgery 49: 1039-1044.

7. Richardson PG, Kassarjian A, Jing W (2004) Case records of the Massachusetts General Hospital. Weekly clinicopathological exercises. Case 38-2004. A 40-year-old man with a large tumor of the skull. N Engl J Med 351: 2637-2645.

8. Blade J, Rosinol L (2007) Complications of multiple myeloma. Hematol Oncol Clin North Am 21: 1231-1246, xi.

9. Kilciksiz S, Karakoyun-Celik O, Agaoglu FY, Haydaroglu A (2012) A review for solitary plasmacytoma of bone and extramedullary plasmacytoma. ScientificWorldJournal 2012: 895765

10. Khouja N, Aouidj L, Bahri K, Jemel H, Haouet S, et al. (2000) [Solitary plasmacytoma of the cranial vault. Case report and review of the literature] Neurochirurgie 46: 43-46.

11. Singh AD, Chacko AG, Chacko G, Rajshekhar V (2005) Plasma cell tumors of the skull. Surg Neurol 64: 434-438.

12. Bindal AK, Bindal RK, van Loveren H, Sawaya R (1995) Management of intracranial plasmacytoma. J Neurosurg 83: 218-221.

13. Jacquet G, Vuillier J, Viennet A, Godard J, Steimle R (1991) [Solitary plasmacytoma simulating pituitary adenoma]. Neurochirurgie 37: 67-71.

14. Strojan P, Soba E, Lamovec J, Munda A (2002) Extramedullary plasmacytoma: clinical and histopathologic study. Int J Radiat Oncol Biol Phys 53: 692-701.

15. Bakar B, Tekkok IH (2012) Plasmocytoma of the skull vault. Turk Neurosurg 22: $95-98$ 